\title{
Article
}

\section{Recognition of lightning-induced trauma to the skeleton: a forensic taphonomic study}

Bacci, Nicholas, Augustine, Tanya, Randolph-Quinney, Patrick, Hunt, Hugh and Nixon, Ken

Available at http://clok.uclan.ac.uk/17508/

Bacci, Nicholas, Augustine, Tanya, Randolph-Quinney, Patrick ORCID: 00000003-0694-5868, Hunt, Hugh and Nixon, Ken (2014) Recognition of lightninginduced trauma to the skeleton: a forensic taphonomic study. 2014

International Conference on Lightning Protection (ICLP) . pp. 1299-1302.

It is advisable to refer to the publisher's version if you intend to cite from the work. http://dx.doi.org/10.1109//CLP.2014.6973330

For more information about UCLan's research in this area go to http://www.uclan.ac.uk/researchgroups/ and search for < name of research Group>.

For information about Research generally at UCLan please go to http://www.uclan.ac.uk/research/

All outputs in CLoK are protected by Intellectual Property Rights law, including Copyright law. Copyright, IPR and Moral Rights for the works on this site are retained by the individual authors and/or other copyright owners. Terms and conditions for use of this material are defined in the policies page.

\section{CLoK}

Central Lancashire online Knowledge www.clok.uclan.ac.uk

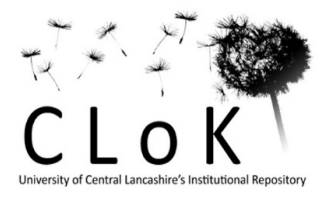




\section{Recognition of lightning-induced trauma to the skeleton: a forensic taphonomic study}

\author{
Nicholas Bacci, Tanya Augustine, Patrick Randolph- \\ Quinney \\ School of Anatomical Sciences, Faculty of Health Sciences \\ University of the Witwatersrand \\ Johannesburg, South Africa
}

\author{
Hugh Hunt, Ken Nixon \\ Electrical \& Information Engineering, University of the \\ Witwatersrand \\ Johannesburg, South Africa
}

\begin{abstract}
Lightning related deaths can be hard to recognize in most circumstances, unless explicitly looked for, and impossible when the remains are fully skeletonized. There is a crucial need for this for forensic authorities in South Africa, where there is a high incidence of lightning deaths and a high rate of recovery of unidentified bodies in the skeletonized state. The effects of a 15 $\mathrm{kA}, 8 / 20 \mu$ s impulse current applied to a series of pig femurs was investigated as well as a comparison with a skeletal element from a giraffe struck by lightning. A distinct pattern of traumatization was observed and is described in detail. Further analysis and comparison to human results should be carried out and a method for accurately identifying lightning related fatalities should be created.
\end{abstract}

Keywords-lightning; forensics; skeleton; taphonomy; electrocution.

\section{INTRODUCTION}

The effects of lightning current flowing through the human body is only somewhat understood from a clinical perspective, but is rarely discussed in forensic pathology and forensic anthropology. The majority of contributions to forensic aspects of electrocution consist of case studies, and these primarily deal with the effects of lightning discharge on the soft tissues [1, 2 and 3].

Cause of death associated with lightning strike and electrocuted victims include ventricular fibrillation, cardiac arrest, respiratory arrest and asphyxia. All the above causes of death can be consistent with certain accidental and naturally occurring deaths, which by default makes them undependable indicators for manner of death identification in the event of lightning; moreover these are not always immediately apparent $[4,5]$. Considering these are the main indicators for lightning strike-related deaths, it can become complex to correctly attribute manner of death without resorting to examining the individual's clothing or personal items for traces of related evidence[6]. Consequently this becomes virtually impossible in the case of completely skeletonized remains, where no soft tissue can be scrutinized for evidence of lightning strike characteristics. However, the effects of lightning passage on the skeleton have been largely ignored.

From the standpoint of forensic death investigation this lack of research is problematic, particularly in a South African context - the country has an annual lightning fatality rate of 10.3 deaths per million people, with the Highveld area alone accounting for over $60 \%$ of those fatalities [7]. South Africa also has an exceptionally high rate of unidentified bodies from natural and deliberate deaths, many of which are recovered in a skeletonized state from veldt and open spaces in both urban and rural contexts; manner and cause of death are often impossible to ascertain, and it would be highly beneficial to recognize and identify criteria which might allow attribution of death by lightning strike in such cases.

Currently no criteria exist which allow for the recognition of lightning as a cause of death in cases of entirely skeletonized remains. This study sets out to determine the effects of lightning discharge on osseous remains, and provide objective, quantifiable criteria which would allow for the assessment of mechanism and cause of death in cases of accidental lightning death where no other forensic evidence is available. This is done by comparing the skeletal remains of a giraffe struck by lightning with pig bones subjected to impulse currents in a high voltage laboratory.

\section{BONE HistOLOGY}

The significance of understanding the microscopic layout of skeletal tissue is paramount when investigating changes undergone by bone tissue at a microscopic level.

\section{A. Basic Bone Histology}

When observed macroscopically, bone is divided in cortical and cancellous [8]. At a microscopic level, cortical bone is comprised mainly of a form of cylindrically organized matrix, where each cylindrical unit is termed an osteon [8]. Each osteon is comprised of a varying number of concentric lamellae (layers) of bone tissue. Within the center of each osteon there is a canal (osteonal canal) which contains a neurovascular bundle [9]. Each of these structures, provide innervation and blood supply/drainage to the surrounding bone tissue and cells [9]. The lamellae are interspersed with bone cells (osteocytes), located in small spaces (lacunae), that function primarily in bone maintenance [9]. These cells extend numerous radiating processes through canaliculi to communicate with each other 
and exchange waste and nutrients with the blood vessels in the osteons [9]. In between the osteons, interstitial lamellae are present, and these have a relatively straight organization [10]. The bone matrix itself is comprised of two components: the inorganic mineral hydroxyapatite and the organic elements of collagen and other non-collagenous proteins [10]. Lastly the periosteum (a layer of connective tissue) surrounds the outermost surface of the bone, whilst the innermost surfaces of the osteonal canals are lined by endosteum [10].

\section{B. Animal Osteon Organization}

For purposes of histological analysis it is important to know the normal histology of the animals observed in this study. The porcine bone appears to have an organization consisting mainly of primary osteons (early bone laid down initially) arranged in wide circumferential layers with smaller areas of compact secondary osteons (mature bone laid down as a replacement for primary osteons) [11, 12]. It is also described as a combination of plexiform (accelerated bone layering with a block system organization) and medium sized secondary osteonic organization in the adult. In the juvenile stages it is considered to be composed largely of lamellar bone comprising primary osteons and plexiform bone with very limited secondary osteonal presence $[11,13]$.

\section{INVESTIGATIONS}

The investigation is a comparison between the skeletal remains of a giraffe struck by lightning and a series of pig femora subjected to impulse currents in a high voltage laboratory.

\section{A. Incidental Investigation}

A proximal component of a juvenile giraffe femur (Giraffa camelopardalis), believed to originate from an animal that fell victim to a lightning event, was donated for the purposes of this study. It was subsequently used as primary comparison to the experimental sample of the study. The femur was firstly assessed for possible evidence of an electrical strike, macroscopically and under low power magnification with the aid of a dissecting microscope. A tibia from a non-lightning struck animal was used as a control.

\section{B. Laboratory Experiment}

For the purpose of this study a high voltage impulse generator was used to subject a series of pig (Sus scrofa domesticus) femora to a $15 \mathrm{kA}, 8 / 20 \mu \mathrm{s}$ impulse current. The investigation was carried out on twelve pig femora. Six were not subjected to the impulse current and used as controls, whilst the other six were experimental.
Figure 1 shows a schematic circuit diagram of the impulse generator used to subject the pig femora to the $15 \mathrm{kA}, 8 / 20 \mu \mathrm{s}$ impulse currents. Each of the six experimental pig femora were

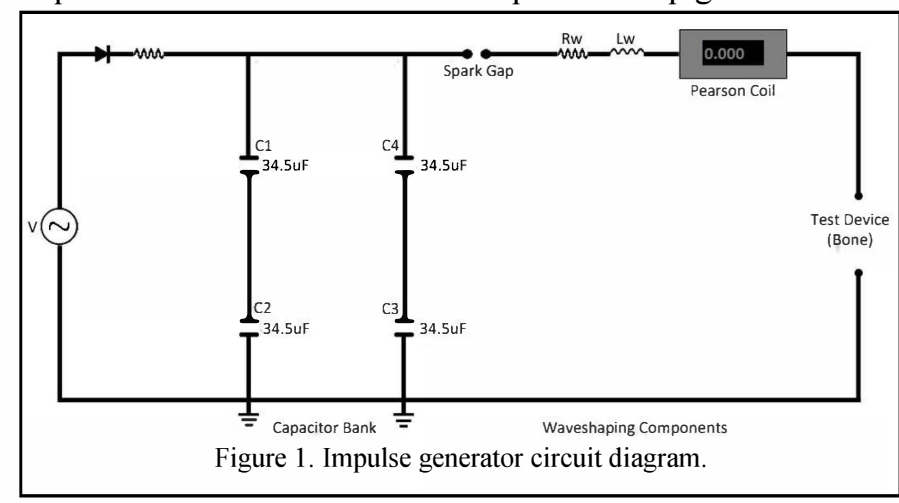

placed in the generator as the Test Device and were held in place by brass electrodes which were inserted on each side of the bone (proximal and distal). The direction of the current was kept consistent throughout all samples. A single $15 \mathrm{kA}, 8 / 20 \mu \mathrm{s}$ impulse current was applied to each of the samples.

\section{Processing of Bone Samples}

The bones from both the deceased giraffe investigation (control and experimental) and the pig femora (control and experimental) from the laboratory experiment were processed. First, the bones were observed macroscopically for signs of surface modification, or gross traumatic defects. They were analyzed microscopically after being ground down into thin sections for transmission light microscopy. The sections were excised with a high speed Clarke CRT40 - 40pce rotary tool equipped with DREMEL cut-off wheel No. 409. The sectioning was done by making two parallel cuts on the anterior aspect of the bone with the rotary tool through the cortex and into the medullary cavity. The preparation process was done as per Maat et al. [14].

Once the section had been removed from the bone it was ground down to an utilizable thickness on waterproof carborundum paper of grit number 220 and lubricated with 6$12 \mathrm{ml}$ of distilled water in order to diminish physical damage to the bone's histological structure. If the thickness allowed for resolution of the histological structures, the section was rinsed twice with distilled water for debridement and dried for two days on filter paper. Sections were then mounted on glass slides with Entellan. Photomicrographs were taken of the most representative slides using a ZEISS Axioskop 2 Plus microscope, AxioCam MRc camera and Axio Vision software, under both bright field and polarized light.

\section{RESULTS AND DISCUSSION}

The results are shown in figure 2, where column A shows the photomicrographs of the control samples (giraffe and pig) and column B shows the experimentally traumatized bones 


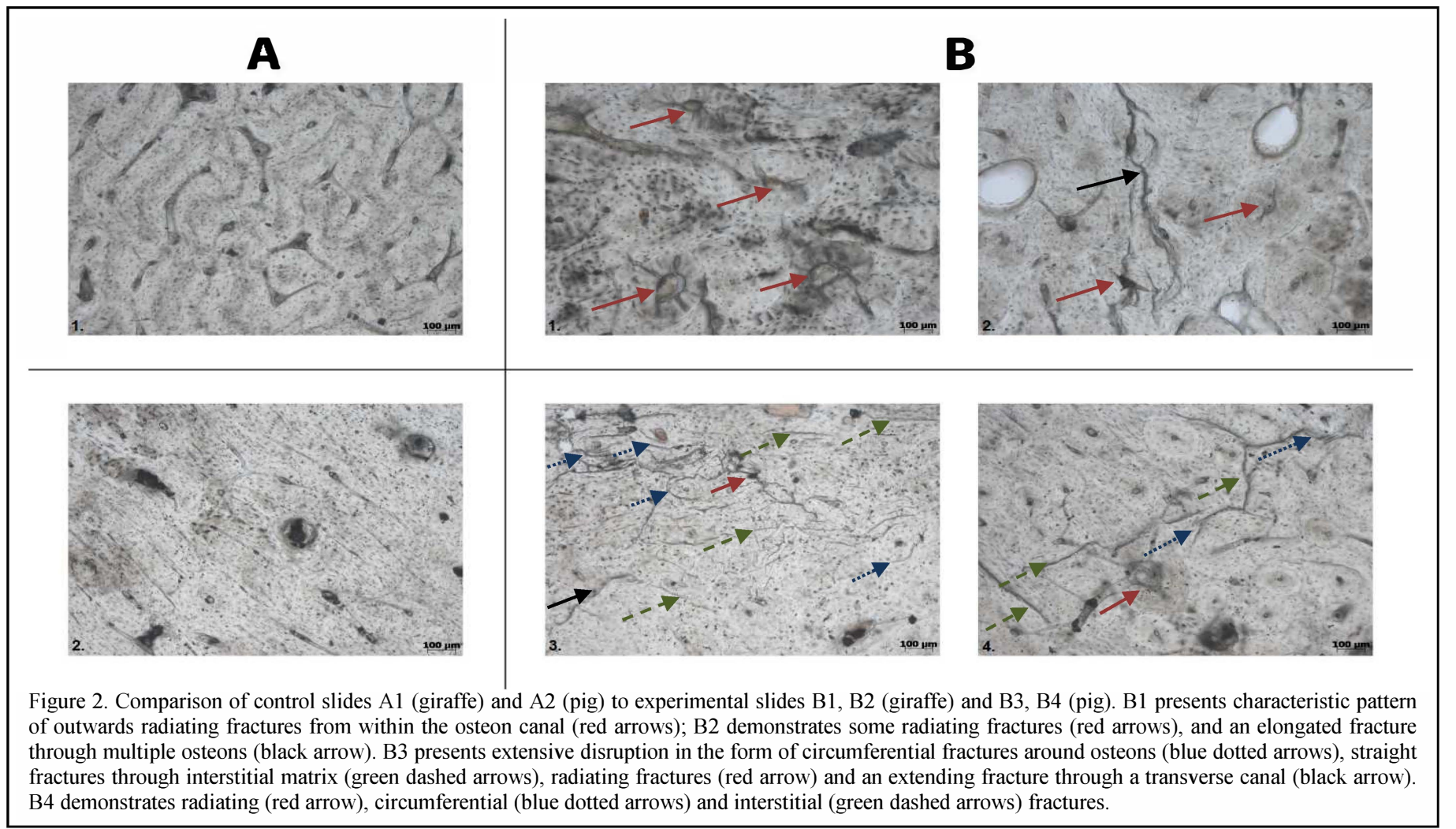

(giraffe and pig). The results appear to indicate a trend between current traversing the bone and macroscopic distortion in the pig femora and microscopic disruption of normal histology in both sample sets. The distortion was observed as superficial scarring on the external postero-lateral aspect area of the bone and was attributed to be caused by arcing over the exterior; this produced demonstrative scarring along with cracking and dehydration of surviving periosteum and soft tissues, and oozing of marrow. The microscopic disruption consisted of a multitude of micro-fractures, attributed to current travelling through the vascular network within the osteonal canals in a living individual (modelled after the giraffe). This was further evidenced by the damaged surrounding osseous matrix and as weakening and irregular micro-fracturing of the matrix in the pig femora.

A number of defined traumatic criteria were identified as differentiating lightning-induced trauma from that of the control bone. These comprise of:

- Circumferential micro-fractures around the osteons

- Straight micro-fractures within interstitial spaces

- Extending micro-fractures propagating from transverse canals

- Outwards radiating micro-fractures from with osteon canal.

These criteria demonstrate distinctly as to the path generally chosen by the current through the vascular network of the bone, as demonstrated by the extensive fracturing in tight association with the osteon network.

\section{CONCLUSION}

This paper presents the first study to definitively demonstrate traumatic defects within bone caused by the passage of lightning current. The superficial modifications materialise in the form of a distortion of the periosteum and are only visible on post-humus electrocution samples. The microscopic evidence reveals additional information in regards to in vivo and post-humus electrocution. Indicative of this is the extent of fracturing almost exclusively on the osseous matrix surrounding the osteon canals in the case of the giraffe sample, while the pig samples demonstrated an overall extent of fracturing post electrocution, but pertained consistent with the pattern observed in the giraffe sample.

The implications of this research warrant an in depth analysis on human skeletal tissue. Which would allow the formulation of a sufficiently accurate method to identify lightning related deaths purely from histological analysis of bone tissue of the deceased becomes plausible.

\section{ACKNOWLEDGEMENTS}

The authors would like to thank Dr Bernard Zipfel, curator of all the Paleosciences collections of the University of the 
Witwatersrand, for donating the lightning struck giraffe sample, Brendon Billings, curator of the Comparative and the Dart collections of the University of the Witwatersrand, for allowing usage of his comparative collection for this study, CBI-electric for funding the Chair of Lightning at the University of the Witwatersrand and for direct support of the Research Group. They would also like to thank Eskom for the support of the Lightning/EMC Research Group through the TESP programme. Thanks are extended to the department of Trade and Industry (DTI) for THRIP funding as well as to the National Research Foundation (NRF) for direct funding of the Research Group.

\section{REFERENCES}

[1] R. K. Wright and J. H. Davis, "The investigation of electrical deaths: a report of 220 fatalities," J Forensic Sci, vol. 25, pp. 514-21, Jul 1980.

[2] E. K. Mitchell and J. H. Davis, "Electrocution by street lighting," $J$ Forensic Sci, vol. 29, pp. 836-42, Jul 1984

[3] P. F. Mellen, et al., "Electrocution: a review of 155 cases with emphasis on human factors," J Forensic Sci, vol. 37, pp. 1016-22, Jul 1992.

[4] T. Bernstein, "Effects of electricity and lightning on man and animals," $J$ Forensic Sci, vol. 18, pp. 3-11, Jan 1973.
[5] M. O'Keefe Gatewood and R. D. Zane, "Lightning injuries," Emerg Med Clin North Am, vol. 22, pp. 369-403, May 2004.

[6] B. D. Lifschultz and E. R. Donoghue, "Deaths caused by lightning," $J$ Forensic Sci, vol. 38, pp. 353-8, Mar 1993.

[7] R. L. Holle. "Annual rates of lightning fatalities by country", 20th International Lightning Detection Conference, pp.1-14. Tucson, Arizona, 2008.

[8] J. B. Kerr, Functional Histology: $2^{\text {nd }}$ ed. Melbourne, Elsevier Mosby Australia, 2010.

[9] M. H. Ross and W. Pawlina, Histology : a text and atlas : with correlated cell and molecular biology, 5th ed. Baltimore, MD: Lippincott Wiliams \& Wilkins, 2006.

[10] A. Mescher, Junqueira's Basic Histology: Text and Atlas, 12th Edition: McGraw-Hill Education, 2009.

[11] J. D. Currey, Bones: Structure and Mechanics: Princeton University Press, 2013

[12] M. Martiniakova, et al., "Histological study of compact bone tissue in some mammals: a method for species determination," International Journal of Osteoarcheology, vol. 17, pp. 82-90, 2007.

[13] M. L. Hillier and L. S. Bell, "Differentiating human bone from animal bone: a review of histological methods," $J$ Forensic $S c i$, vol. 52, pp. 249-63, Mar 2007.

[14] G. J. R. Maat, R. P. M. Van Den Bos \& M. J. Arents. "Manual preparation of ground sections for the microscopy of natural bone tissue: update and modification of Frost's 'rapid manual method", International Journal of Osteoarchaeology, vol. 11, pp. 366-374, 2001. 